\title{
Early Infectious Complications of Bone Marrow Transplantation in Total Protective Environment
}

\author{
Hisashi Funada, Toshihiko Machi and Tamotsu Matsuda \\ Protected Environment Unit and The Third Department of Medicine, Kanazawa University \\ School of Medicine, 13-1, Takara-machi, Kanazawa, Ishikawa, 920
}

(Received for publication, June 3, 1989)

\begin{abstract}
Bone marrow transplantation was performed on 68 patients with severe hematologic disorders and solid tumors on the total protective environment program using laminar-airflow isolation and decontamination procedures. Patients were evaluated for infection acquisition while isolated. Sixty-four patients (94\%) became febrile after the conditioning treatment, but evidence of infection proved absent in $23(36 \%)$ of them. Viral infection occurred in 30 patients $(44 \%)$, bacterial infection in 17 patients $(25 \%)$, and fungal infection in 1 patient $(1 \%)$. The infectious complications included orolabial herpes simplex (28 patients), septicemia (11 patients), local catheter infection ( 6 patients), anoperineal cellulitis and periodontitis (5 patients each), viral interstitial pneumonia (3 patients), and herpes zoster, bacterial pneumonia, and dacryocystitis (1 patient each). The most common causative bacteria, Pseudomonas aeruginosa and Staphylococcus epidermidis, tended to be isolated as a monoflora or a pure culture from the throat and/or stool or infection sites just before or at the onset of fever. Five patients $(7 \%)$ died of infection while isolated. Anoperineal cellulitis with or without bacteremia proved fatal in 4 patients, of whom 3 had become febrile within the 2 weeks before transplant. It was, thus, suggested that the strict enforcement of prophylactic measures based on the results of surveillance cultures may be associated with a reduced incidence of septicemia, hence reduced mortality. In addition, it was stressed that scrutiny of residual infections such as seen in periodontal and anorectal areas before transplant will reduce serious bacterial infection soon after transplant.
\end{abstract}

Key words: bone marrow transplantation; laminar-airflow isolation; intestinal decontamination; infectious complications

Bone marrow transplantation has come into wide use as one of the state-ofthe-art therapeutic modalities for hematologic disorders with marrow failure, immunodeficiency states, and some solid tumors (27). However, infection remains 
a major cause of morbidity and mortality in the early granulocytopenic period after transplant, although deaths due purely to infection have greatly diminished $(1,2,19,20,30,32-34)$. Total protective environment, which consists essentially of isolation in a laminar-airflow room and intestinal decontamination, is the most sophisticated, but not invariably successful, infection control program during granulocytopenia $(1,2,9,18,20)$. The purpose of this paper is to report our experience of early infectious complications of bone marrow transplantation inside such an environment and discuss some problems involved in infection acquisition.

\section{PATIENTS AND METHODS}

\section{Transplant Patients}

Between October 1977 and November 1988, 68 patients with severe hematologic disorders and solid tumors admitted to the Third Department of Medicine, Kanazawa University, for bone marrow transplantation were placed on the total protective environment program. The other 4 patients, who were all autotransplanted, received an infection prophylaxis regimen in a conventional room and were excluded from this study.

Details on the methods of allogeneic and autologous marrow transplantation have been described elsewhere (11-13). Syngeneic marrow transplantation was performed according to the method of autologous marrow transplantation. The day of marrow infusion was designated day 0 . All patients received marrowlethal cytoreductive chemotherapy with or without total body irradiation prior to marrow grafting. All allotransplant patients also received methotrexate and/or cyclosporine as graft-versus-host-disease prophylaxis $(26,27)$. All patients had central venous catheters such as a Hickman right atrial catheter inserted several days before the conditioning regimen was started $(21,31)$.

\section{Total Protective Environment Program}

Details on the isolation and decontamination procedures have been described elsewhere (9). Briefly, vertical laminar-airflow rooms were used for this study. Decontamination procedures, including skin cleansing and the administration of oral nonabsorbable antibiotics and sterile food, were begun as soon as the patients entered the laminar-airflow rooms, usually at the latest by the day before the conditioning was carried out. The oral nonabsorbable antibiotics for intestinal decontamination consisted of gentamicin, vancomycin, and nystatin. Antibiotic inhalation was added for more effective decontamination of the oropharynx. All fomites entering the rooms were gas- or steam-sterilized. Staff members with access to patients in isolation were required to wear sterile cap, mask, gown, gloves, and boots. All patients were maintained on the total protective environment program until the granulocyte level exceeded $500 / \mathrm{mm}^{3}$ after the posttransplant nadir. Granulocytopenia was defined as a granulocyte count of below $500 / \mathrm{mm}^{3}$.

All patients had surveillance cultures taken of specimens from the throat, stool, and urine before antibiotic prophylaxis and then at least once weekly while 
in isolation (9). Cultures were also obtained from other sites as clinically indicated. The organisms isolated were identified by the criteria of Cowan and Steel (5) and also according to the description in the Bergey's manual of systematic bacteriology $(15,25)$ and the manual of clinical microbiology (16). Antibiotic sensitivities were determined by a triple disk method using Tridisks (Eiken).

Suspected as well as documented bacterial infections were usually treated with a $\beta$-lactam antibiotic (a cephalosporin or an antipseudomonal penicillin) and an aminoglycoside in combination (8). Patients, moreover, with fever refractory from 4 to 7 days of such antibacterial therapy, were treated with additional intravenous amphotericin B.

\section{Infection Evaluation and Documentation}

Febrile patients were closely examined for signs of infection because of the poor inflammatory response associated with granulocytopenia (23).

The diagnosis of septicemia was based on at least 1 positive blood culture and on clinical manifestations that could be produced by the circulating organisms $(8)$. Catheter-related septicemia was defined as at least 1 positive blood culture combined with a positive semiquantitative culture of the catheter tip and/or development of apparent inflammation at the skin exit of the catheter (catheter exit site infection) $(17,21)$. Pneumonia was diagnosed when the patient had a compatible chest film and clinical presentation, or evidence of this infection at autopsy study. The presence of localized infections such as periodontitis, cellulitis, and dacryocystitis was established on the basis of clinical signs and symptoms. On the other hand, patients were considered to have a herpesvirus infection such as stomatitis, varicella (or herpes zoster), or interstitial pneumonia if a compatible clinical picture was associated with viral isolation, a fourfold or greater increase in antibody titer and/or histological evidence, viz., characteristic intranuclear inclusion bodies. Viral isolation, if clinically indicated, was done from a mucocutaneous lesion such as a vesicle or an ulcer, and from either bronchoalveolar lavage fluid or lung tissue obtained by biopsy or at autopsy. Titers of antibody to herpes simplex virus, varicella-zoster virus, and cytomegalovirus were determined by complement fixation test, indirect fluorescence technique, and enzyme-linked immunosorbent assay before transplant and every 2 to 4 weeks thereafter. Both virus isolation and determination of antiviral antibody titers were carried out at Special Reference Laboratory, Tokyo.

Statistics

The chi-square test with Yates' correction was used for statistical analysis.

\section{RESULTS}

\section{Patient Characteristics}

Patient characteristics are shown in Table 1. Allotransplantation was performed on 53 patients $(78 \%$ ), autotransplantation on 14 patients $(21 \%$ ), and 
Table 1. Characteristics of patients undergoing bone marrow transplantation in the total protective environment

\begin{tabular}{|c|c|c|c|c|c|}
\hline & & \multicolumn{3}{|c|}{ Bone marrow transplantation } & \multirow[b]{2}{*}{$\begin{array}{c}\text { Total } \\
(n=68)\end{array}$} \\
\hline & & $\begin{array}{l}\text { Allogeneic } \\
(n=53)\end{array}$ & $\begin{array}{c}\text { Autologous } \\
(n=14)\end{array}$ & $\begin{array}{l}\text { Syngeneic } \\
\quad(n=1)\end{array}$ & \\
\hline \multirow{2}{*}{ Age, years } & Median & 23 & 28 & 25 & 25 \\
\hline & Range & $9-46$ & $11-52$ & & $9-52$ \\
\hline & le/Female & $25 / 28$ & $10 / 4$ & $1 / 0$ & $36 / 32$ \\
\hline \multicolumn{6}{|c|}{ Underlying disease, no. } \\
\hline \multicolumn{2}{|c|}{ Aplastic anemia } & 2 & & & 2 \\
\hline \multicolumn{2}{|c|}{ Acute leukemia } & 36 & 2 & 1 & 39 \\
\hline \multicolumn{2}{|c|}{ Chronic leukemia } & 10 & & & 10 \\
\hline \multicolumn{2}{|c|}{$\mathrm{RAEB}^{a}$ ) in transformation } & 2 & & & 2 \\
\hline \multicolumn{2}{|c|}{ Malignant lymphoma } & 3 & 7 & & 10 \\
\hline \multicolumn{2}{|c|}{ Solid tumor } & & 5 & & 5 \\
\hline
\end{tabular}

a) refractory anemia with excess blasts.

syngeneic transplantation on 1 patient $(1 \%)$. Seven patients $(10 \%)$, who were all allotransplanted, died while in isolation.

\section{Duration of Granulocytopenia}

The granulocyte count exceeded $500 / \mathrm{mm}^{3}$ a median of 27 days after transplant (range 15 to 104 days) in 61 patients who completed the total protective environment program. There was no difference in recovery of marrow function by transplant type (a median of 28 days posttransplant for 46 allotransplant patients, a median of 27 days posttransplant for 14 autotransplant patients, and 29 days posttransplant for 1 patient transplanted from his identical twin). Incidentally, the median duration of severe posttransplant granulocytopenia of below $100 / \mathrm{mm}^{3}$ was 14 days ( 3 to 79 days) for the same patient population. In such a setting, laminar-airflow isolation for a total of 68 patients was started a median of 10 days before transplant ( 4 to 45 days) and was discontinued a median of 28 days after transplant (6 to 105 days), extending over a median period of 42 days (12 to 115 days).

\section{Febrile Patients}

Sixty-four (94\%) of the 68 transplant patients developed a fever of above $38.0^{\circ} \mathrm{C}$ in close relation to a falling granulocyte count. All the patients had been afebrile before undergoing strict isolation and decontamination procedures. Fever occurred a median of 6 days after transplant ( -15 to 30 days), with a median duration of 10 days in isolation ( 1 to 46 days). Clinical or microbiological evidence of infection, however, proved absent in $23(36 \%)$ of these febrile patients. On the other hand, 4 allotransplant patients $(6 \%)$ remained afebrile throughout the entire posttransplant course. 


\section{Infection Acquisition}

Table 2 presents the infections acquired by transplant patients while they were receiving the isolation and decontamination procedures. Viral infection occurred in 30 patients $(44 \%)$ (23 allotransplanted and 7 autotransplanted), bacterial infection in 17 patients (25\%) (14 allotransplanted, 2 autotransplanted, and 1 syngeneic-marrow-transplanted), and fungal infection in 1 allotransplant patient $(1 \%)$. Orolabial herpes simplex (28 patients, $41 \%$ ) was the most commonly observed infection, followed in decreasing order by septicemia (11 patients, 16\%), catheter exit site infection (6 patients, $9 \%$ ), anoperineal cellulitis and periodontitis ( 5 patients, $7 \%$, each), viral interstitial pneumonia (3 patients, $4 \%$ ), and localized

Table 2. Infectious complications of bone marrow transplantation in the total protective environment

\begin{tabular}{|c|c|c|c|c|c|}
\hline \multirow{2}{*}{ Site and organism } & \multicolumn{3}{|c|}{ Bone marrow transplantation } & & \\
\hline & $\begin{array}{l}\text { Allogeneic } \\
\quad(n=53)\end{array}$ & $\begin{array}{l}\text { Autologous } \\
(n=14)\end{array}$ & $\begin{array}{l}\text { Syngeneic } \\
(n=1)\end{array}$ & \multicolumn{2}{|l|}{$\begin{array}{c}\text { Total } \\
(n=68)\end{array}$} \\
\hline Herpes simplex, orolabial & 21 & 7 & & 28 & \\
\hline Interstitial pneumonia & 3 & & & 3 & \\
\hline Cytomegalovirus & & & & & 3 \\
\hline Herpes zoster, facial & & 1 & & 1 & \\
\hline Septicemia & $10^{a)}$ & 1 & & 11 & \\
\hline Staphylococcus epidermidis & & 1 & & & 4 \\
\hline Staphylococcus aureus & & & & & 1 \\
\hline Pseudomonas aeruginosa & & & & & 2 \\
\hline Klebsiella pneumoniae & & & & & 1 \\
\hline Enterobacter cloacae & & & & & 1 \\
\hline Fusobacterium nucleatum & 2 & & & & 2 \\
\hline Candida guilliermondii & & & & & 1 \\
\hline Pneumonia & 1 & & & 1 & \\
\hline Pseudomonas aeruginosa & & & & & 1 \\
\hline Cellulitis, anoperineal & 5 & & & 5 & \\
\hline Staphylococcus aureus & & & & & 1 \\
\hline Pseudomonas aeruginosa & & & & & 2 \\
\hline Enterobacter cloacae & & & & & 1 \\
\hline Serratia marcescens & & & & & 1 \\
\hline Periodontal infection & 5 & & & 5 & \\
\hline Pseudomonas aeruginosa & & & & & 3 \\
\hline Klebsiella pneumoniae & & & & & 1 \\
\hline Fusobacterium nucleatum & & & & & 1 \\
\hline Dacryocystitis & & 1 & & 1 & \\
\hline Pseudomonas aeruginosa & & 1 & & & 1 \\
\hline Catheter infection, local & 5 & & 1 & 6 & \\
\hline Staphylococcus epidermidis & 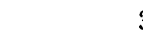 & & & & 3 \\
\hline Staphylococcus aureus & & & 1 & & 1 \\
\hline Pseudomonas cepacia & & & & & 1 \\
\hline Candida guilliermondii & & & & & 1 \\
\hline
\end{tabular}


Table 3. Frequency of infection, by relapse or remission status at the time of allotransplantation, among patients with acute leukemia

\begin{tabular}{lcc}
\hline & \multicolumn{2}{c}{ Hematologic status } \\
\cline { 2 - 3 } & $\begin{array}{c}\text { Relapse } \\
(n=15)\end{array}$ & $\begin{array}{c}\text { Remission } \\
(n=21)\end{array}$ \\
\hline No. (\%) of patients infected & $11(73)$ & $10(48)$ \\
No. of patient infections & 19 & 19 \\
Viral & 9 & 8 \\
Bacterial & 10 & 11 \\
No. of episodes of infection per patient & 1.7 & 1.9 \\
No. of patients with infectious death & 2 & 2 \\
\hline
\end{tabular}

herpes zoster, bacterial pneumonia, and dacryocystitis (1 patient, 1\%, each). One allotransplant patient developed 2 separate episodes of septicemia while isolated.

With regard to bacterial infection, most of the causative organisms were isolated as a monoflora or a pure culture from the throat and/or stool or infection sites just prior to or at the onset of fever. Pseudomonas aeruginosa was the species most frequently isolated. Seven patients $(10 \%)$ had $P$. aeruginosa infections with or without bacteremia. Three of the 7 isolates proved resistant to gentamicin. Four episodes were closely associated with the new acquisition of $P$. aeruginosa despite the isolation procedures, while the other 3 were caused by persisting strains which had been recovered prior to the patient entry into the laminar-airflow room. On the other hand, the second largest group was Staphylococcus epidermidis, which acted as the most frequent causative organism of septicemia and catheter exit site infection exclusively.

Patients with acute leukemia, who formed the largest group among allotransplant patients, were evaluated for infection acquisition by pretransplant hematologic status (Table 3). Infection developed slightly more often among patien ts with acute leukemia in relapse at the time of transplantation than among patients whose disease was in remission. There was, however, no difference in infection acquisition between the 2 groups.

\section{Septicemia}

Septicemia was the most frequent of the bacterial and fungal infections. Threefourths of a total of 12 episodes of septicemia occurred at a granulocyte level of below $100 / \mathrm{mm}^{3}$. The site of origin could be ascertained in $9(75 \%)$ of the episodes (Table 4). Septicemia occurred most often during anoperineal cellulitis, followed by periodontitis and catheter exit site infection. These 3 sites accounted for two-thirds of the episodes.

$S$. epidermidis was the most frequent causative organism. All the 4 patients with $S$. epidermidis septicemia had an indwelling Hickman catheter. There was, however, only 1 patient with documented catheter-related septicemia due to this organism. No source of infection could be identified in the other 3 episodes, 
Table 4. Sites of origin of septicemia

\begin{tabular}{|c|c|}
\hline Site and organism & No. of episodes \\
\hline Cellulitis, anoperineal & 4 \\
\hline Pseudomonas aeruginosa & 2 \\
\hline Enterobacter cloacae & 1 \\
\hline Staphylococcus aureus & 1 \\
\hline Periodontal infection & 2 \\
\hline Klebsiella pneumoniae & 1 \\
\hline Fusobacterium nucleatum & 1 \\
\hline Catheter infection, local & 2 \\
\hline Staphylococcus epidermidis & 1 \\
\hline Candida guilliermondii & 1 \\
\hline Herpes simplex, orolabial & 1 \\
\hline Fusobacterium nucleatum & 1 \\
\hline Unidentified & 3 \\
\hline Staphylococcus epidermidis & 3 \\
\hline Total & 12 \\
\hline
\end{tabular}

Table 5. Early infectious death in the total protective environment

\begin{tabular}{cc}
\hline (Total no. of cases) & No. of fatal cases \\
\hline Infection & 5 \\
Septicemia $(n=11)$ & 3 \\
Cellulitis, anoperineal $(n=5)$ & $4^{a)}$ \\
Pneumonia, bacterial $(n=1)$ & 1 \\
\hline
\end{tabular}

Fever $\left(>38.0^{\circ} \mathrm{C}\right)$ persisting for $>48 \mathrm{hr}$ within 2 weeks before transplant $\left.(n=7) \quad 3^{b}\right)$

a) Three of them developed septicemia from anoperineal cellulitis.

b) All of them developed anoperineal cellulitis immediately after transplant.

although surveillance cultures revealed colonization of the throat and/or stool with the organism in small numbers.

\section{Early Infectious Death}

Five allotransplant patients died with serious bacterial infection while in isolation, accounting for $7 \%$ of all the 68 transplant patients. Fatal infections included anoperineal cellulitis with or without bacteremia (4 cases) and pneumonia (1 case) (Table 5). P. aeruginosa was isolated from 3 cases, and Serratia marcescens and Staphylococcus aureus from 1 case each. Two of the $3 P$. aeruginosa isolates were newly acquired despite the prophylactic measures. On the other hand, 3 of the 7 patients who had had a fever of above $38.0^{\circ} \mathrm{C}$ continuing for longer than $48 \mathrm{hr}$ within 2 weeks before transplant died early in the granulocytopenic period after transplant. Anoperineal cellulitis proved fatal to these 3 patients.

\section{DISCUSSION}

Infection remains a complication with considerable morbidity and mortality 
just before and soon after marrow transplant $(1,2,19,20,30,32-34)$. As shown in this study, almost all patients experience fever during the posttransplant granulocytopenic period, but often without clinical or microbiological evidence of infection (32). This is probably because severe granulocytopenia is closely associated with a poor inflammatory response $(23,32)$.

It has been reported that nearly one-half of the transplant patients housed outside the protective environment developed septicemia in the first month after transplant $(1,34)$. The frequency of septicemia in the present study was $16 \%$, which proved to be about one-third the rate hitherto reported $(1,34)$. This reduction in frequency was therefore inferred to reflect the effectiveness of the isolation and decontamination procedures used $(1,20)$. Indeed, the incidence of death from bacterial or fungal infection within the initial 30 days after transplant turned out to be $7 \%$ in the present series, which is almost equal to the less than $10 \%$ at the University of California at Los Angeles (32).

It is argued, however, that despite the reduced rates of infection and infectious death in the granulocytopenic period after transplant, the total protective environment program has had little effect on the long-term survival of transplant patients (1). In fact, long-term survival depends largely upon subsequent complications such as interstitial pneumonia and recurrent leukemia, which are unrelated to both isolation and decontamination (1).

Anoperineal cellulitis was the most frequent source of septicemia, often with fatal outcome, in the present study. Furthermore, patients with this major local infection tended to develop a fever persisting for longer than $48 \mathrm{hr}$ within 2 weeks before transplant, although fever usually occurred about a week after transplant. On the other hand, it is well-known that anorectal lesions occur commonly in granulocytopenic patients with acute leukemia receiving intensive chemotherapy (23). It is therefore suggested that patients with acute leukemia, especially those 2 have survived a severe anorectal infection in close association with prior chemotherapy, should be evaluated with scrutiny for a residual infection before transplant. This may be the key to reducing early infectious deaths inside the protective environment.

The types of infection during the granulocytopenic period after marrow infusion were essentially the same as those observed in patients with cancer receiving intensive chemotherapy $(10,23)$. Pneumonia usually occurs as frequently as septicemia in the latter patients (10). Despite the relatively frequent development of septicemia, however, bacterial pneumonia is uncommonly encountered $(19,34)$, as indicated in our series of transplant patients. This is also the case in patients housed outside the protected environment $(19,34)$. It is probably because either the early use of empiric antibiotics, the absence of a normal inflammatory response associated with severe granulocytopenia, the difficulty in obtaining pulmonary specimens by aggressive diagnostic methods such as transtracheal aspiration in patients with severe thrombocytopenia, or any combination may obscure the presence of pneumonia $(19,34)$. On the other hand, the risk of air-borne fungal infections such as aspergillosis can be greatly diminished by the entry into an air-filtered environment (29).

The organisms, gentamicin-resistant $P$. aeruginosa among others, which persisted 
or newly appeared in the throat and/or stool despite the isolation and decontamination procedures, tended to cause major local infections, followed often by septicemia, in the granulocytopenic period after transplant. Indeed, mutliply drugresistant strains of $P$. aeruginosa are likely to predominate on wards such as hematology/oncology units, where antibiotics are used in large amounts $(8)$. Moreover, acquisition of such strains is usually associated with irregular ingestion or discontinuation of prophylactic oral nonabsorbable antibiotics, which are quite unpalatable to patients receiving intensive chemoradiotherapy followed by oral mucositis (24). On the other hand, both overgrowth and new acquisition of aerobic gramnegative bacilli in patients' flora are prevented as long as anaerobic flora remains intact, namely while colonization resistance is maintained (28). It is, therefore, suggested that both strict application of aseptic techniques and regular intake of the oral antibiotics are important to prevent transplant patients in isolation from being contaminated with aerobic gram-negative bacilli such as $P$. aeruginosa, and that, in patients with gentamicin-resistant $P$. aeruginosa colonization, this drug be replaced by either an appropriate aminoglycoside antibiotic or polymyxin B. Thus, surveillance cultures may be useful for the early identification of highly resistant organisms such as $P$. aeruginosa which are likely to cause subsequent septicemia in granulocytopenic patients $(4,8,10,18,23,32)$, although some investigators questioned the significance of such cultures because of the poor cost-effectiveness (14).

It has recently been noted that the predominant pathogens in blood cultures are changing from gram-negative organisms to gram-positive organisms such as S. epidermidis $(4,18,19,30)$. This organism was associated exclusively with septicemia and catheter exit site infection in the present study. Moreover, S. epidermidis occurs on the skin surface as well as deep in sebaceous glands. The increasing frequency of $S$. epidermidis septicemia appeared, therefore, to parallel the general use of central venous catheters (31). However, it is also suggested that the respiratory tract and alimentary canal may be the major sources of septicemia due to $S$. epidermidis in granulocytopenic patients (29), as is rather in accord with the culture results obtained from most of our cases.

Periodontal infection occurred as often as anoperineal infection and local catheter infection. This was considered to reflect not only that gingival crevices are as difficult to decontaminate as the sebaceous glands mentioned just above, since adequate topical antibiotic levels cannot be attained $(6,7,9)$, but also that pre-existing mild gingivitis, which is known to be a very widespread and common affliction in the normal adult population (6), may be aggravated because of the mucosal breakdown and severe granulocytopenia produced by the conditioning chemoradiotherapy $(18,23)$.

Orolabial herpes simplex as a consequence of virus reactivation, which cannot be prevented by the total protective environment, was the most common type of infection soon after transplant (34). It was associated with moderate morbidity but with no mortality in the early period after transplant. In this sense, acylovir prophylaxis may well be justified at least for herpes simplex virus antibodypositive patients. It is argued, however, that prophylactic acyclovir may con- 
tribute to the development of a resistant variant of herpes simplex virus $(3,22)$. On the other hand, oral herpes simplex virus infection proved to be a risk for early septicemia in only 1 of our cases, although the breakdown of mucosal barriers, which occurs after the preparative chemoradiotherapy, is considered to predispose to microbial bloodstream invasion in granulocytopenic patients $(18,23,34)$.

In conclusion, it was suggested from the present study that the total protective environment for patients undergoing bone marrow transplantation, combined with monitoring by surveillance cultures, may be associated with a reduced incidence of septicemia, hence reduced mortality. In addition, it was emphasized that close evaluation of residual infections such as seen in dental and anorectal areas before transplant will reduce serious bacterial infection after transplant.

Acknowledgments. The authors thank the nursing and medical staff who took medical and psychologic care of the patients discussed in this manuscript.

\section{REFERENCES}

(1) Buckner, C.D., R.A. Clift, J.E. Sanders, J.D. Meyers, G.W. Counts, V.T. Farewell, E.D. Thomas, and The Seattle Marrow Transplant Team. 1978. Protective environment for marrow transplant recipients: a prospective study. Ann. Intern. Med. 89: 893-901.

(2) Buckner, C.D., R.A. Clift, E.D. Thomas, J. Hersman, J.E. Sanders, P.S. Stewart, J.C. Wade, M. Murphy, G. Counts, and J.D. Meyers. 1983. Early infectious complications in allogeneic marrow transplant recipients with acute leukemia: effects of prophylactic measures. Infection 11: 243-250.

(3) Burns, W.H., R. Saral, G.W. Santos, O.L. Laskin, P.S. Lietman, C. McLaren, and D.W. Barry. 1982. Isolation and characterization of resistant herpes simplex virus after acyclovir therapy. Lancet 1: 421-423.

(4) Cohen, M.L., M.T. Murphy, G.W. Counts, C.D. Buckner, R.A. Clift, and J.D. Meyers. 1983. Prediction by surveillance cultures of bacteremia among neutropenic patients treated in a protected environment. J. Infect. Dis. 147: 789-793.

(5) Cowan, S.T., and K.J. Steel. 1973. Manual for the identification of medical bacteria, Cambridge University Press, London.

(6) Duncan, J.L. 1985. Dental infections and other diseases of the oral cavity, p. 266-286. In G.P. Youmans, P.Y. Paterson and H.M. Sommers (eds.), The biologic and clinical basis of infectious diseases, 3rd ed., W.B. Saunders Co., Philadelphia.

(7) Funada, H., S. Fujita, K. Niwa, and K. Hattori. 1979. The significance of propionibacteria in bone marrow cultures. Jpn. J. Med. 18: 1-5.

(8) Funada, H., T. Machi, and T. Matsuda. 1988. Bacteremia complicating acute leukemia with special reference to its incidence and changing etiological patterns. Jpn. J. Clin. Oncol. 18: 239-248.

(9) Funada, H., H. Teshima, and K. Hattori. 1983. Total intestinal decontamination for prevention of infection in bone marrow transplantation. Jpn. J. Clin. Oncol. 13 (Suppl. 1): 111-126.

(10) Funada, H., H. Teshima, and K. Hattori. 1984. Infection in patients with acute leukemia. Jpn. J. Clin. Pathol. 32: 959-966 (in Japanese).

(11) Harada, M., T. Yoshida, H. Funada, C. Ishino, H. Kodo, T. Mori, K. Matsue, S. Shiobara, K. Odaka, S. Ohtake, H. Teshima, K. Kondo, M. Yamamura, S. Nakao, M. Ueda, S. Nakamura, and K. Hattori for The Kanazawa University Bone Marrow Transplant Team. 1982. Combined-modality therapy and autologous bone marrow transplantation in the treatment of advanced non-Hodgkin's lymphoma and solid tumor: the Kanazawa experience. Transplant. Proc. 14: 733-737. 
(12) Harada, M., T. Yoshida, H. Funada, H. Kodo, T. Mori, C. Ishino, K. Matsue, S. Shiobara, S. Ohtake, K. Odaka, H. Teshima, K. Kondo, S. Nakao, M. Ueda, S. Nakamura, and K. Hattori. 1982. Allogeneic bone marrow transplantation for the treatment of acute leukemia: the Kanazawa experience. Jpn. J. Clin. Oncol. 12: 301-314.

(13) Hattori, K., M. Harada, T. Yoshida, C. Ishino, H. Funada, H. Kodo, T. Mori, K. Matsue, S. Shiobara, K. Odaka, S. Ohtake, H. Teshima, K. Kondo, M. Yamamura, S. Nakao, M. Ueda, and S. Nakamura. 1982. A preliminary report on autologous bone marrow transplantation for the treatment of advanced non-Hodgkin's lymphoma. Jpn. J. Clin. Oncol. 12: 171180.

(14) Kramer, B.S., P.A. Pizzo, K.J. Robichaud, F. Witesbsky, and R. Wesley. 1982. Role of serial microbiologic surveillance and clinical evaluation in the management of cancer patients with fever and granulocytopenia. Am. J. Med. 72: 561-568.

(15) Krieg, N.R., and J.G. Holt (eds.). 1984. Bergey's manual of systematic bacteriology, Vol. 1 Williams \& Wilkins, Baltimore.

(16) Lennette, E.H., A. Ballows, W.J. Hansler Jr., and H.J. Shadomy (eds.). 1985. Manual of clinical microbiology, 4th ed., American Society for Microbiology, Washington, D.C.

(17) Maki, D.G. 1982. Infections associated with intravascular lines, p. 309-363. In J.S. Remington and M.N. Swartz (eds.), Current clinical topics in infectious diseases, Vol. 3, McGraw-Hill Book Co., New York.

(18) Meyers, J.D. 1985. Infection in recipients of bone marrow transplants, p. 261-292. In J.S. Remington and M.N. Swartz (eds.), Current clinical topics in infectious diseases, Vol. 6, McGraw-Hill Book Co., New York.

(19) Meyers, J.D., and E.D. Thomas. 1982. Infection complicating bone marrow transplantation, p. 507-551. In R.H. Rubin and L.S. Young (eds.), Clinical approach to infection in the immunocompromised host, Plenum Press, New York.

(20) Petersen, F.B., C.D. Buckner, R.A. Clift, S. Lee, N. Nelson, G.W. Counts, J.D. Meyers, J.E. Sanders, P.S. Stewart, W.I. Bensinger, R. Navari, and E.D. Thomas. 1986. Laminar air flow isolation and decontamination: a prospective randomized study of the effects of prophylactic systemic antibiotics in bone marrow transplant patients. Infection 14: 115-121.

(21) Press, O.W., P.G. Ramsey, E.B. Larson, A. Fefer, and R.O. Hickman. 1984. Hickman catheter infections in patients with malignancies. Medicine 63: 189-200.

(22) Saral, R., W.H. Burns, O.L. Laskin, G.W. Santos, and P.S. Lietman. 1981. Acyclovir prophylaxis of herpes-simplex-virus infection: a randomized, double-blind, controlled trial in bonemarrow-transplant recipients. N. Engl. J. Med. 305: 63-67.

(23) Schimpff, S.C. 1975. Diagnosis of infection in patients with cancer. Eur. J. Cancer 11 (Suppl.): 29-38.

(24) Schimpff, S.C., W.H. Greene, V.M. Young, C.L. Fortner, L. Jepsen, N. Cusack, J.B. Block, and P.H. Wiernik. 1975. Infection prevention in acute nonlymphocytic leukemia. Laminar air flow room reverse isolation with oral nonabsorbable antibiotic prophylaxis. Ann. Intern. Med. 82: 351-358.

(25) Sneath, P.H.A., N.S. Mair, and J.G. Holt (eds.). 1986. Bergey's manual of systematic bacteriology, Vol. 2, Williams \& Wilkins, Baltimore.

(26) Storb, R., H.J. Deeg, J. Whitehead, F. Appelbaum, P. Beatty, W. Bensinger, C.D. Buckner, R. Clift, K. Doney, V. Farewell, J. Hansen, R. Hill, L. Lum, P. Martin, R. McGuffin, J. Sanders, P. Stewart, K. Sullivan, R. Witherspoon, G. Yee, and E.D. Thomas. 1986. Methotrexate and cyclosporine compared with cyclosporine alone for prophylaxis of acute graft versus host disease after marrow transplantation for leukemia. N. Engl. J. Med. 314: 729-735.

(27) Thomas, E.D., R. Storb, R.A. Clift, A. Fefer, F.L. Johnson, P.E. Neiman, K.G. Lerner, H. Glucksberg, and C.D. Buckner. 1975. Bone-marrow transplantation. N. Engl. J. Med. 292: 832-843, 895-902.

(28) van der Waaij, D., and J.M. Berghuis-de Vries. 1974. Selective decontamination of enterobacteriaceae species from the digestive tract in mice and monkeys. J. Hyg. 72: 205-211.

(29) Wade, J.C., S.C. Schimpff, K.A. Neiman, and P.H. Wiernik. 1982. Staphylococcus epidermidis: 
an increasing cause of infection in patients with granulocytopenia. Ann. Intern. Med. 97: 503508.

(30) Watson, J.G. 1983. Problems of infection after bone marrow transplantation. J. Clin. Pathol. 36: $683-692$.

(31) Winston, D.J., D.V. Dudnick, M. Chapin, W.G. Ho, R.P. Gale, and W.J. Martin. 1983. Coagulase-negative staphylococcal bacteremia in patients receiving immunosuppressive therapy. Arch. Intern. Med. 143: 32-36.

(32) Winston, D.J., W.G. Ho, R.E. Champlin, and R.P. Gale. 1984. Infectious complications of bone marrow transplantation. Exp. Hematol. 12: 205-215.

(33) Winston, D.J., R.P. Gale, D.V. Meyer, L.S. Young, and The UCLA Bone Marrow Transplantation Group. 1979. Infectious complications of human bone marrow transplantation. Medicine 58: $1-31$.

(34) Zaia, J.A. 1983. Infections, p. 131-176. In K.G. Blume and L.D. Petz (eds.), Clinical bone marrow transplantation, Churchill Livingstone, New York. 